\title{
Xác định vi khuẩn Acinetobacter calcoaceticus - Acinetobacter baumannii complex kháng kháng sinh carbapenem phân lập trong rau ăn sống và thịt chế biến sẵn trên địa bàn thành phố Hà Nội
}

\author{
Tạ Thị Yến*, Phạm Thị Loan, Ninh Thị Hạnh, Vũ Thị Hải Hà \\ Phạm Văn Quân, Nguyễn Thành Trung
}

Viện Kiểm nghiệm an toàn vệ sinh thực phẩm quốc gia, Hà Nội, Việt Nam

(Ngày đến tòa soạn: 26/12/2020; Ngày chấp nhận đăng: 18/03/2021)

\section{Tóm tắt}

Acinetobacter spp. là vi khuẩn gây bệnh phổ biến ở người. Chi Acinetobacter bao gồm khoảng 65 loài, trong đó nhóm Acinetobacter calcoaceticus - Acinetobacter baumannii complex được xác định là nguyên nhân gây ra hơn $80 \%$ trường hợp nhiễm trùng tại bệnh viện ở bệnh nhân suy giảm miễn dịch. Các phân tích kiểu hình hiện có không đủ để xác định chính xác và phân biệt các loài Acinetobacter spp. quan trọng về mặt lâm sàng. Trong tổng số 480 mẫu rau ăn sống và thịt chế biến sẵn được thu thập tại 06 quận nội thành Hà Nội gồm Đống Đa, Hoàng Mai, Hai Bà Trưng, Long Biên, Hà Đông, Cầu Giấy, có 288 mẫu (chiếm 60\%) nhiễm Acinetobacter spp. Kết quả định danh bằng kỹ thuật MALDI-TOF MS ghi nhận 208 mẫu $(43 \%, \mathrm{n}=480)$ nhiễm Acinetobacter calcoaceticus-Acinetobacter baumannii complex, trong đó 156 mẫu rau ăn sống $(65 \%, \mathrm{n}=240)$ và 52 mẫu thịt $(22 \%, \mathrm{n}=240)$ nhiễm Acinetobacter calcoaceticus-Acinetobacter baumannii complex. Thử nghiệm kháng sinh đồ bằng các khoanh giấy kháng sinh cho thấy $82 \%$ số chủng vi khuẩn Acinetobacter calcoaceticus-Acinetobacter baumannii complex kháng với kháng sinh imipenem và $30 \%$ số chủng kháng với meropenem.

Tưk khóa: Acinetobacter spp., Acinetobacter calcoaceticus-Acinetobacter baumannii complex, MALDI-TOF MS, carbapenem.

\section{1. ĐẠT VẤN ĐỀ}

Vi khuẩn Acinetobacter spp. là vi khuẩn gây bệnh phổ biến gây ra các triệu chứng nhiễm trùng máu, nhiễm khuẩn bệnh viện và tiêu chảy. Ngoài môi trường bệnh viện, vi khuẩn Acinetobacter spp. cũng đã được tìm thấy trong thực phẩm như rau, táo, dưa, cải bắp, súp lơ, rau diếp, dưa chuột, ớt, phòng bệnh, củ cải, cà rốt cũng như các loại củ như khoai tây và ngũ cốc như ngô ngọt. Acinetobacter spp. cũng được xem là nguyên nhân gây hỏng thịt xông khói, thịt gà, thịt lợn, cá và trứng ngay cả khi chúng được bảo quản trong tủ lạnh hoặc sau khi chiếu xạ gamma [1].

Trong các loài vi khuẩn thuộc chi Acinetobacter thì Acinetobacter calcoaceticusAcinetobacter baumannii complex là tập hợp gồm 04 loài vi khuẩn có khả năng gây bệnh đã được phân lập từ đất, nước và thực phẩm bao gồm thịt, cá, trái cây và rau, làm dấy lên lo ngại 
thực phẩm có thể là nguôn lây nhiễm tiềm ẩn cho con người, đặc biệt là trong các cơ sở y tế [1].

Bên cạnh đó, hiện tượng vi khuẩn kháng đa kháng sinh (MDR) là vấn đề quan ngại trong điều trị đối với các bệnh nhiễm trùng mắc phải tại bệnh viện và cộng đông. Tổ chức Y tế Thế giới gần đây đã xác định tình trạng kháng thuốc kháng sinh là một trong ba vấn đề quan trọng mà con người đang phải đối mặt. Các vi khuẩn kháng đa kháng sinh nghiêm trọng và phổ biến nhất được xác định là các loài Enterococcus faecium, Staphylococcus aureus, Klebsiella pneumoniae, Acinetobacter baumannii, Pseudomonas aeruginosa và Enterobacter spp. [2]. Tại Việt Nam, Bộ Y tế đã ban hành các thông tư và tài liệu hướng dẫn về kháng sinh sử dụng trong điều trị. Dựa trên Hướng dẫn sử dụng kháng kháng sinh (Ban hành kèm theo Quyết định số 708/QĐ-BYT ngày 02/3/2015) tác dụng trên Acinetobacter baumannii và Thông tư 19/2018/TT-BYT vể Ban hành danh mục thuốc thiết yếu điều trị nhiễm khuẩn, các kháng sinh carbapenem đang được khuyến cáo sử dụng điều trị nhiễm khuẩn Acinetobacter baumannii, đặc biệt là imipenem và meropenem.

Rau và thịt là nguồn thực phẩm phổ biến trong cuộc sống hằng ngày của người Việt Nam. Theo báo cáo của Ngân hàng thế giới vào năm 2017, tỉ lệ tiêu thụ rau tại Việt Nam là $0,4 \mathrm{~kg}$ rau mỗi ngày trên người và tỉ lệ tiêu thụ rau tại Hà Nội là 2.800 tấn mỗi ngày [3]. Theo Niên giám thống kê năm 2019, sản lượng giết mổ và bán ra của gia cầm, thịt lợn tại Hà Nội là 1302,5 và 3328,8 nghìn tấn [4]. Từ đó cho thấy rau và thịt là nguôn tiêu thụ chính cho nhu cầu ăn uống hằng ngày của người dân Hà Nội. Cũng như các loại thực phẩm khác, thịt và rau ăn sống là nguồn chứa vi sinh vật gây bệnh, và có thể lây truyền chủng vi khuẩn kháng kháng sinh lên người. Vi khuẩn Acinetobacter calcoaceticus-Acinetobacter baumannii complex đã được phát hiện trong một số loại thực phẩm. Tuy nhiên cho đến nay chưa có báo cáo nào về thực trạng nhiễm Acinetobacter calcoaceticus-Acinetobacter baumannii complex trong rau ăn sống và sản phẩm thịt kháng kháng sinh được tiêu thụ tại Hà Nội được bán tại các quán bán đổ ăn sẵn để cung cấp dữ liệu về thực trạng thực phẩm nhiễm vi khuẩn kháng kháng sinh carbapenem tại Hà Nội cũng như Việt Nam.

Trong nghiên cứu này, chúng tôi tiến hành xác định sự lưu hành và tỉ lệ kháng kháng sinh carbapenem của Acinetobacter calcoaceticus-Acinetobacter baumannii complex trong mẫu rau ăn sống và thịt chế biến sẵn bán tại các cửa hàng bán đô ăn sẵn.

\section{VẬT LIỆU VÀ PHƯƠNG PHÁP NGHIÊN CỨU}

\section{1. Đối tượng nghiên cứu}

Các vật liệu được sử dụng trong nghiên cứu này gồm:

- Sử dụng phương pháp nghiên cứu mô tả điều tra cắt ngang, thu thập mẫu ngẫu nhiên và dựa trên công thức cỡ mẫu để xác định lượng mẫu tiến hành nghiên cứu:

+ 240 mẫu thịt chế biến sẵn (sản phẩm từ thịt lợn, vịt, gà: thịt lợn quay, giò, chả, vịt nướng, gà luộc).

+ 240 mẫu rau ăn sống bán kèm các sản phẩm thịt (rau diếp, xà lách, húng láng, húng quế, mùi ta, mùi tàu, ngổ, hành,...).

- Địa điểm thu thập mẫu: tại các cửa hàng bán đô ăn có kèm rau ăn sống trên địa bàn 06 quận nội thành Hà Nội, bao gồm: Đống Đa, Hoàng Mai, Hai Bà Trưng, Long Biên, Hà Đông, Cầu Giấy. 
- Thời gian thu thập mẫu: Năm 2019 - 2020.

- Các mẫu sau đó được bảo quản tại phòng thí nghiệm ở nhiệt độ $4^{\circ} \mathrm{C}-8^{\circ} \mathrm{C}$ và được phân tích trong ngày hoặc vào ngày hôm sau.

\subsection{Hóa chất, chất chuẩn}

\subsubsection{Hóa chất và dụng cu}

Các hóa chất chính được sử dụng trong nghiên cứu bao gồm: Buffer Peptone water (Merck, Đức), TSA agar (Merck, Đức), chromagar Acinetobacter (Chromagar), Mueller Hinton agar (Merck, Đức), VITEK MS-CHCA (Biomerieux, Mỹ), khoanh giấy kháng sinh carbapenem (Liofilchem, Ý), mipenem (IMP, $10 \mu \mathrm{g}$ ), meropenem (MRP, $10 \mu \mathrm{g}$ ).

Các dụng cụ được sử dụng bao gồm: Đĩa petri vô trùng (Corning, Mỹ), que cấy vô trùng (Biologix, Mỹ), khay Vitek (Biomerieux, Mỹ).

\subsubsection{Chủng chuân}

Phát hiện Acinetobacter baumannii trên rau, tính kháng kháng sinh: sử dụng chủng E. coli ATCC 25922, chủng Acinetobacter baumannii được phân lập trên mẫu bệnh phẩm của bệnh nhân tại Bệnh viện Thanh Nhàn [5]. Chủng thu nhận từ Bệnh viện đã được giải trình tự, so sánh với dũ liệu ngân hàng Gen Hoa Kỳ (https://blast.ncbi.nlm.nih.gov/Blast.cgi), xác định độ tương đông 100\% với chủng Acinetobacter baumannii 2008S11-069.

Định danh vi khuẩn bằng kỹ thuật khối phổ thời gian bay sử dụng nguôn tia laser với sự trợ giúp của chất nền (MALDI TOF), sử dụng chủng E. coli ATCC 8739.

\subsection{Thiết bị}

Nôi hấp (Hymaraya, Nhật), tủ sấy (Sanyo, Nhật), cân kỹ thuật D = 0,1 ML802 (Metter Toledor, Thụy Sĩ), tủ ấm (Memert, Đức), tủ an toàn sinh học cấp 2 (Bio II, Anh), máy đông nhất mẫu (Anh), hệ thống VITEK MS (Biomerieux, Mỹ).

\subsection{Phương pháp nghiên cứu}

\subsubsection{Phát hiện Acinetobacter spp. bằng phương pháp nuôi cấy truyền thống}

Việc phát hiện Acinetobacter spp. theo phương pháp truyển thống được thực hiện theo các bước như sau:

- Cân mẫu: Cân $25 \mathrm{~g}$ (từ 0,1 kg rau hoặc thịt đã được đồng nhất).

- Tăng sinh $25 \mathrm{~g}$ mẫu trong $225 \mathrm{~mL}$ đệm peptone kép. Tiến hành nuôi qua đêm $37^{\circ} \mathrm{C} / 18 \pm 2 \mathrm{~h}$.

- Ria lên môi trường Chromagar Acinetobacter có bổ sung chất bổ sung [6].

- Thu nhận các khuẩn lạc màu đỏ là Acinetobacter spp.

2.4.2. Định danh Acinetobacter calcoaceticus-Acinetobacter baumannii complex bằng kỹ thuật MALDI TOF

Các bước tiến hành định danh vi khuẩn bằng kỹ thuật MALDI TOF trên thiết bị VITEK MS theo hướng dẫn của nhà sản xuất thiết bị, cụ thể như sau:

- Bước 1: Chủng vi khuẩn được nuôi trên môi trường TSA ở $37^{\circ} \mathrm{C} / 24 \mathrm{~h}$. 
- Bước 2: Vi khuẩn được phết lên từng giếng của khay.

- Bước 3: Nhỏ 0,1 $\mu \mathrm{L}$ dung dịch CHCA.

- Bước 4: Quét mã khay, nhập mã mẫu vào phân mềm Malditof preparation.

- Bước 5: Phân tích trên thiết bị.

- Bước 6: Đọc kết quả trên phần mềm Myla.

2.4.3. Xác định tính kháng kháng sinh của vi khuân Acinetobacter calcoaceticus-Acinetobacter baumannii complex bằng kỹ thuật kháng sinh đồ

Tính kháng kháng sinh của Acinetobacter calcoaceticus-Acinetobacter baumannii complex được thử nghiệm bằng các khoanh giấy kháng sinh theo qui trình hướng dẫn của tổ chức sức khỏe động vật thế giới [7], cụ thể như sau:

- Bước 1: Tạo dung dịch chủng Acinetobacter calcoaceticus-Acinetobacter baumannii complex: $10^{6}-10^{8} \mathrm{CFU} / \mathrm{mL}$.

- Bước 2: Sử dụng bông tăm vô trùng dàn dịch chủng Acinetobacter calcoaceticusAcinetobacter baumannii complex lên đĩa thạch Muller Hinton agar.

- Bước 3: Hong khô ở nhiệt độ phòng và đặt khoanh giấy kháng sinh có chứa kháng sinh (nồng độ và các kháng sinh được thể hiện trong (Bảng 1).

- Bước 4: Đo kích thước vòng kháng, đối chiếu với kích thước của chủng đối chiếu (E. coli ATCC 25922, A. baumannii đối chưng) theo hướng dẫn của tổ chức Phòng Thí nghiệm và lâm sàng Hoa Kỳ về chuẩn kháng sinh theo Bảng 1 [8].

- Bước 5: Đọc kết quả: kháng, nhạy cảm, không kháng.

Bảng 1. Kháng sinh, nông độ kháng sinh và điểm đọc kháng sinh đồ (kháng, trung gian, không kháng)

\begin{tabular}{ccccccc}
\hline $\begin{array}{c}\text { Kháng sinh } \\
\text { Carbapenem }\end{array}$ & Tên viết tắt & $\begin{array}{c}\text { Nồng độ } \\
\text { kháng sinh }(\boldsymbol{\mu} g)\end{array}$ & \multicolumn{3}{c}{ Điểm đọc tiêu chuẩn } \\
\hline Imipenem & IMI & 10 & $\geq 22$ & $19-21$ & $\leq 18$ \\
\hline Meropenem & MRP & 10 & $\geq 18$ & $13-17$ & $\leq 14$ \\
\hline
\end{tabular}

\section{KẾT QUẢ VÀ BÀN LUẬN}

\subsection{Sự lưu hành vi khuẩn Acinetobacter calcoaceticus-Acinetobacter baumannii complex}

\subsubsection{Tỉ lệ nhiễm vi khuân Acinetobacter spp. trong thịt và rau sống}

Nghiên cứu tiến hành phân tích phát hiện và định lượng vi khuẩn Acinetobacter spp. trong 480 mẫu thịt chế biến sẵn và rau ăn sống tại các quán bán đồ ăn có kèm rau ăn sống thuộc 06 Quận nội thành Hà Nội từ năm 2019 - 2020. Các chủng vi khuẩn màu đỏ xuất hiện trên môi trường Chromagar Acinetobacter có bổ sung kháng sinh được xác định là Acinetobacter spp. (Hình 1). 

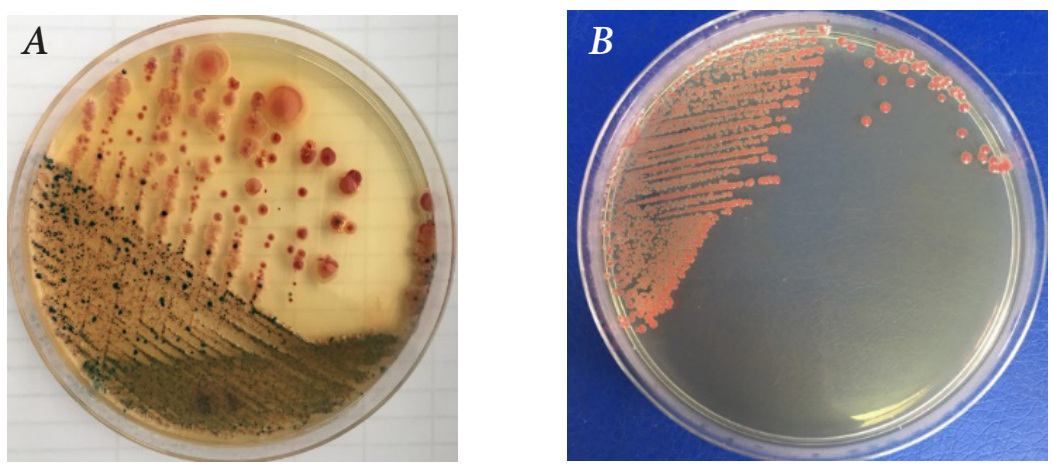

Hinh 1. Vi khuân Acinetobacter spp. trên thạch Chromagar Acinetobacter

Chủng vi khuẩn Acinetobacter phân lập từ mẫu

Chủng vi khuẩn $A$. baumannii đối chứng

Kết quả phân tích 480 mẫu cho thấy có tới 288 mẫu (chiếm 60\%) nhiễm Acinetobacter spp., trong đó có $178 / 240$ mẫu rau (chiếm $74 \%$ ) và $110 / 240$ mẫu thịt (chiếm $46 \%$ ) nhiễm Acinetobacter spp. Xét theo thời gian, năm 2019, trong tổng số 240 mẫu được lấy có 165/240 mẫu rau và thịt (65\%) nhiễm Acinetobacter spp. Năm 2020, tỉ lệ nhiễm Acinetobacter spp. trong 240 mẫu thu thập cho tỉ lệ thấp hơn với 123/240 mẫu nhiễm, chiếm 51\%. (Bảng 2).

Bảng 2. Ti lệ nhiễm Acinetobacter spp. trong thịt chế biến sãn và rau ăn sống

\begin{tabular}{|c|c|c|c|c|c|c|}
\hline \multirow{2}{*}{ Thực phẩm } & \multicolumn{2}{|c|}{$2019(n=240)$} & \multicolumn{2}{|c|}{$2020(n=240)$} & \multicolumn{2}{|c|}{$2019-2020(n=480)$} \\
\hline & $\begin{array}{c}\text { Mẫu } \\
\text { nhiễm }\end{array}$ & Ti lệnhiễm & Mẫu nhiễm & $\begin{array}{c}\text { Ti lệ } \\
\text { nhiếm }\end{array}$ & Mễu nhiễm & Tì lệ nhiễm \\
\hline $\begin{array}{l}\text { Thịt chế } \\
\text { biến sã̃n } \\
(n=240)\end{array}$ & 63 & $53 \%$ & 47 & $39 \%$ & 110 & $46 \%$ \\
\hline $\begin{array}{c}\text { Rau ăn } \\
\text { sống } \\
(n=240)\end{array}$ & 102 & $85 \%$ & 76 & $63 \%$ & 178 & $74 \%$ \\
\hline Tổng & 165 & $65 \%$ & 123 & $51 \%$ & 288 & $60 \%$ \\
\hline
\end{tabular}

Kết quả phân tích của nghiên cứu này tương đồng với các kết quả ở nhiều nước trên thế giới về sự hiện diện của vi khuẩn Acinetobacter spp. trên đối tượng rau ăn sống nhửng có tỉ lệ nhiễm cao hơn. Trong một nghiên cứu của Berlau và cộng sự [9] được thực hiện năm 1999 ghi nhận tỉ lệ nhiêm Acinetobacter spp. trong mẫu rau và quả tươi là $17 \%$. Nghiên cứu của HamitonMiler và Shah (2001) cho thấy sự xuất hiện của 02 chủng Acinetobacter spp. trên mẫu rau salad ăn sống [10]. Tại Hồng Kông (2001), 51\% mẫu rau $(\mathrm{n}=21)$ nhiễm Acinetobacter spp [11]. Kết quả nghiên cứu của chúng tôi cho thấy tỉ lệ nhiễm Acinetobacter spp. trong rau ăn sống (74\%) thấp hơn nghiên cứu của Carvalheira và cộng sự (2017), thực hiện tại Bồ Đào Nha, đã ghi nhận 86,7\% rau diếp nhiễm Acinetobacter spp. [12]. 
Sự nhiễm các vi khuẩn Acinetobacter spp. có tỉ lệ cao trên rau ăn sống được xác định có thể do lây nhiễm trong quá trình trông trọt bắt nguôn từ nguôn nước tưới và đất, hoặc một nguyên nhân thường thấy tại các nước đang phát triển là rau có thể được rửa tại nguôn nước ô nhiễm trước khi phân phối ra thị trường. Trong sản xuất nông nghiệp, rau nhiễm các vi sinh vật gây bệnh có thể liên quan tới quá trình sử dụng nước ao và nước sông để rửa rau, cách thức xử lý rau của người trông rau và lưu trũ rau ở những nơi bị ô nhiễm. Các nghiên cứu trên thế giới và trong nước đều cho thấy sự hiện diện của vi khuẩn trong nước rửa rau, rau ăn sống và sự ô nhiễm vi sinh lên sản phẩm thực vật bởi nguôn chất thải của con người là một thực tế tại các nước đang phát triển, nông nghiệp canh tác theo mô hình vườn ao chuông. Sự lây truyền vi khuẩn từ nguồn nước lên rau sống xảy ra trong quá trình trồng trọt đã được biết đến như là một con đường lây nhiễm trong chuỗi cung ứng thực phẩm và là một hiện tượng tất yếu. Điêu này lý giải cho sự nhiễm khuẩn Acinetobacter spp. trong rau ăn sống thu thập trên địa bàn Hà Nội với tỉ lệ cao chiếm $74 \%$, khi tại Việt Nam vẫn còn các vùng thâm canh, sử dụng nguôn nước tưới chưa qua kiểm soát chất lượng để trồng rau, và dễ dàng bắt gặp hình ảnh những người nông dân, người bán hàng rửa rau tại các ao hồ, kênh mương trước khi đưa đi tiêu thụ.

Kết quả nghiên cứu này của chúng tôi có sự tương đông về sự có mặt của vi khuẩn Acinetobacter spp. với các nghiên cứu của các tác giả khác trên thế giới trong thịt chế biến sẵn, tuy khác nhau về tỉ lệ nhiễm. Nghiên cứu của Chalchisa và Kenasa tại Nigeria (2019) trên thịt chế biến sẵn trong cửa hàng ăn của Trường đại học Wollega, cho thấy $10.3 \%$ mẫu nhiễm Acinetobacter spp. [13]. Một nghiên cứu khác của Oranusl và Bralde [14] cho thấy sự hiện diện của Acinetobacter spp. trong bánh thịt. Trong đó, chủng vi khuẩn này được xác định là 01 trong 03 chủng vi sinh vật là nguyên nhân gây hỏng thịt trong nghiên cứu của Lulietto và cộng sự [15]. Sự ô nhiễm Acinetobacter spp. trong sản phẩm thịt chế biến sẵn có thể là do quá trình xử lý, cắt lát, đóng gói, và làm lạnh. Nguồn gốc của sự lây nhiễm có thể đến từ các nguyên liệu thô được sử dụng đã dẫn đến sự lây nhiễm Acinetobacter spp. trong sản phẩm thịt và môi trường nhà bếp nơi chế biến sản phẩm thịt [15].

\subsection{2. Định danh vi khuân Acinetobacter calcoaceticus-Acinetobacter baumannii complex}

288 chủng vi khuẩn Acinetobacter spp. thu thập được từ các mẫu nghiên cứu và tiến hành định danh xác định nhóm vi khuẩn Acinetobacter calcoaceticus-Acinetobacter baumannii complex bằng kỹ thuật MALDI-TOF trên thiết bị VITEK MS. Kết quả cho thấy 208/288 (72\%) chủng Acinetobacter spp. là Acinetobacter calcoaceticus-Acinetobacter baumannii complex được xác định với độ tương đông 99,9\%, tương đương với 43\% (208/480) mẫu rau và thịt nhiễm Acinetobacter calcoaceticus-Acinetobacter baumannii complex. Trong đó 156/178 chủng phân lập từ mẫu rau và 52/110 chủng phân lập từ mẫu thịt là Acinetobacter calcoaceticus-Acinetobacter baumannii complex, lân lượt là $88 \%$ và $47 \%$ trong nhóm Acinetobacter spp. đã được phân lập; tương đương $65 \%(\mathrm{n}=240)$ mẫu rau ăn sống và $22 \%(\mathrm{n}=240)$ mẫu thịt nhiễm Acinetobacter calcoaceticus-Acinetobacter baumannii complex.

\subsection{Vi khuẩn Acinetobacter calcoaceticus-Acinetobacter baumannii complex kháng kháng sinh carbapenem}

Kết quả kiểm tra khoanh giấy kháng sinh thu được tỉ lệ kháng carbapenem cao trên các chủng Acinetobacter calcoaceticus-Acinetobacter baumannii complex được thu thập (Bảng 3). Tỉ lệ kháng kháng sinh được phát hiện với $82 \%$ và $30 \%$ của chủng vi khuẩn Acinetobacter calcoaceticusAcinetobacter baumannii complex tương ứng với kháng với kháng sinh imipenem và meropenmem. 
Bảng 3. Tính kháng kháng sinh carbapenem của vi khuân Acinetobacter calcoaceticusAcinetobacter baumannii complex

\begin{tabular}{ccccc}
\hline $\begin{array}{c}\text { Kháng sinh } \\
\text { carbapenem }\end{array}$ & Tên viết tắt & $\begin{array}{c}\text { Nồng độ kháng } \\
\text { sinh }(\mu)\end{array}$ & Số chủngkháng & Ti lệ kháng(\%) \\
\hline Imipenem & IMI & 10 & 171 & 82 \\
\hline Meropenem & MRP & 10 & 62 & 30 \\
\hline
\end{tabular}

Tỉ lệ kháng kháng sinh thuộc nhóm carbapenem (imipenem và meropenem) trên sản phẩm thịt và rau ăn sống cao với các chủng Acinetobacter calcoaceticus-Acinetobacter baumannii complex phân lập được trên mẫu bệnh phẩm của bệnh nhân. Trong nghiên cứu của Tran và cộng sự thực hiện từ năm 2010 - 2014 tại 03 bệnh viện lớn tại Hà Nội (Việt Đức, Thanh Nhàn và Xanh Pôn), cho thấy 23/528 chủng kháng carbapenem [16]. Điều này cho thấy thực phẩm có thể là vật chủ trung gian lây truyền vi khuẩn Acinetobacter calcoaceticus-Acinetobacter baumannii complex lên người. Tỷ lệ kháng kháng sinh thuộc nhóm carbapenem cao (82\% với immipenem và $30 \%$ với meropenem) có thể xuất phát từ việc sử dụng kháng sinh carbapenem cho điều trị bệnh nhiễm khuẩn do Acinetobacter baumannii tại các bệnh viện. Nguôn nước thải từ bệnh viện có chứa mầm bệnh, phát tán ra môi trường khi chưa xử lý, sẽ phát tán mầm bệnh chứa gen kháng kháng sinh lên các thực phẩm (rau sống, thịt tươii, ...) trong quá trình chăn nuôi, trồng trọt và giết mổ.

\section{KẾT LUẬN}

Kết quả nghiên cứu trên 480 mẫu rau và thịt sống thu thập tại các cửa hàng bán đô ăn sẵn ở 06 quận nội thành Hà Nội cho thấy vi khuẩn Acinetobacter spp. được phát hành trên 288 mẫu $(60 \%)$, trong đó, 208 mẫu $(43 \%, \mathrm{n}=480)$ nhiễm Acinetobacter calcoaceticus-Acinetobacter baumannii complex với 156 mẫu rau ăn sống $(65 \%, \mathrm{n}=240)$ và 52 mẫu thịt $(22 \%, \mathrm{n}=240)$. Trong đó, $82 \%$ và $30 \%$ chủng vi khuẩn Acinetobacter calcoaceticus-Acinetobacter baumannii complex đã được phân lập $(\mathrm{n}=208)$ kháng với kháng sinh imipenem và meropenem.

\section{TÀI LIỆU THAM KHẢO}

[1]. H. J. Doughari, P. A. Ndakidemi, I. S. Human, \& S. Benade, "The Ecology, Biology and Pathogenesis of Acinetobacter spp.: An Overview," Microbes Environments, vol. 26, no. 2, pp. 101-112, 2011.

[2]. A. Howard, M. O’Donoghue, A Feeney, \& R. D. Sleator, “Acinetobacter baumannii: An emerging opportunistic pathogen," Virulence, vol. 3, no. 3, pp. 243-250, 2012.

[3]. World Bank, Vietnam food safety risks management: challenges and opportunities: Quản lý nguy cơ an toàn thực phẩm ở Việt Nam: nhũng thách thức và cơ hội (Vietnamese). Washington, D.C.: World Bank Group, 2017.

[4]. Tổng cục thống kê, Niên giám thống kê. Nhà xuất bản thống kê. Hà Nội: Nhà xuất bản Thống Kê, 2019.

[5]. Bệnh viện Thanh Nhàn, "Đề tài: Nghiên cứu qui trình chế tạo bộ kit Multiplex Realtime 
PCR phát hiện một số tác nhân thường gặp gây nhiếm khuẩn bệnh viện tại các bệnh viện Hà Nội," mã số 01C-08/02-2016, 2016 - 2018.

[6]. A. Y. Ciftci, E. Karakece, A. R. Atasoy, G. Asik, and I. H. Ciftci, "Culture media for detection of Acinetobacter baumannii selective media for detection of A. baumannii," Journal of Microbioly and Experimentation, vol. 2, no. 3, pp. 87-90, 2015.

[7]. World Organisation for Animal Health, "Chapter 2.1.1 Laboratory Methodologies for Bacterial Antimicrobial Susceptibility Testing," OIE Manual of diagnostic tests and vaccines for Terrestrial Animals, 2019.

[8]. Clinical and Laboratory Standard Institute, Performance Standards for Antimicrobial Susceptibility Testing, 2019.

[9]. J. Berlau, H. M. Aucken, E. Houang, T. L. Pitt, "Isolation of Acinetobacter spp. including A. baumannii from vegetables: implications for hospital-acquired infections", Journal of Hospital Infection, vol. 42, 201-204, 1999.

[10]. J. M. T. Hamilton-MillerSarojShah, "Identity and antibiotic susceptibility of enterobacterial flora of salad vegetables," International Journal of Antimicrobial Agents, vol. 18, no. 1, pp. $81-83,2001$.

[11]. E. T. Houang, Y. W. Chu, C. M. Leung, K. Y. Chu, J. Berlan, K. C. Ng, and A. F. B. Chong, "Epidemiology and infection control implications of Acinetobacter spp. in Hong Kong," Journal Clinical Microbiology, vol. 39, no.1, pp. 228-234, 2001.

[12]. A. Carvalheira, Joana Silva, Paula Teixeira, "Acinetobacter spp. in food and drinking water - A review," Food Microbiology, 2020.

[13]. W. Chalchisa \& G. Kenasa, "Microbial Quality and Safety of Ready-to-Eat Foods in Cafeterias around Wollega University, Nekemte Campus (Ethiopia)," Research \& Reviews: Journal of Food and Dairy Technology, 2019.

[14]. U. S. Oranusi \& W. Braide, "A study of microbial safety of ready-to-eat foods vended on highways: Onitsha-Owerri, south east Nigeria," International Research Journal of Microbiology, vol. 3, no. 2, pp. 066-071, 2012.

[15]. M. F. Lulietto, P. Sechi, E. Borgogni, and B. T. Cenci-Goga, "Meat Spoilage: A Critical Review of a Neglected Alteration Due to Ropy Slime Producing Bacteria," Italian Journal of Animal Science, vol. 14, no. 3, pp. 4011, 2015.

[16]. D. N. Tran, H. H. Tran, M. Matsui, M. Suzuki, K. Shibayama, T. D. Pham, T. T. Van Phuong, D. A. Dang, H. S. Trinh, C. T. Loan, L. T. V. Nga, H. R. Van. Doom, and H. F. L. Wertheim, "Emergence of New Delhi metallo-beta-lactamase 1 and other carbapenemase-producing Acinetobacter calcoaceticus-baumannii complex among patients in hospitals in Ha Noi, Viet Nam," European Journal of Clinical Microbiology and Infectious Diseases, vol. 36, pp. 219-225, 2017. 


\title{
Identification of carbapenem - resistant Acinetobacter calcoaceticus - Acinetobacter baumannii complex in ready-to-eat vegetables and meats in Hanoi
}

\author{
Ta Thi Yen, Pham Thi Loan, Ninh Thi Hanh, Vu Thi Hai Ha \\ Pham Van Quan, Nguyen Thanh Trung \\ National Institute for Food Control, Hanoi, Vietnam
}

\section{Abstract}

Acinetobacter spp. are common pathogenic bacteria. The Acinetobacter genus includes 65 species, of which the Acinetobacter calcoaceticus-Acinetobacter baumannii complex group has been identified as the cause of more than $80 \%$ of hospital infections in immunocompromised patients. Existing phenotypic techniques are not sufficient to accurately identify and distinguish clinically important Acinetobacter spp. In total of 480 samples including raw vegetables and processed meat which collected in six districts of Hanoi (Dong Da, Hoang Mai, Hai Ba Trung, Long Bien, Ha Dong, Cau Giay) in which 288 samples (60\%) were contaminated with Acinetobacter spp. The results of identification by MALDI-TOF MS technique recorded $208(43 \%, \mathrm{n}=480)$ of samples contaminated with Acinetobacter calcoaceticus-Acinetobacter baumannii complex, of which $156(65 \%, \mathrm{n}=240)$ of vegetables and $52(22 \%, \mathrm{n}=240)$ of meat samples. Antibiotic susceptibility tests using antibiotic paper strips showed that $82 \%$ of Acinetobacter calcoaceticusAcinetobacter baumannii complex strains were resistant to imipenem and $30 \%$ of the complex was resistant to meropenem.

Keywords: Acinetobacter spp., Acinetobacter calcoaceticus-Acinetobacter baumannii complex, MALDI-TOF MS, carbapenem. 